Synthesis, part of a Special Feature on Assessing Risks to Wildlife

\title{
Assessing Risks to Wildlife Populations from Multiple Stressors: Overview of the Problem and Research Needs.
}

\author{
Wayne R. Munns, Jr. ${ }^{1}$
}

\begin{abstract}
Wildlife populations are experiencing increasing pressure from human-induced changes in the landscape. Stressors including agricultural and urban land use, introduced invasive and exotic species, nutrient enrichment, direct human disturbance, and toxic chemicals directly or indirectly influence the quality and quantity of habitat used by terrestrial and aquatic wildlife. Governmental agencies such as the U.S. Environmental Protection Agency are required to assess risks to wildlife populations, in its broadest definition, that result from exposure to these stressors, yet considerable uncertainty exists with respect to how such assessments should be conducted. This uncertainty is compounded by questions concerning the interactive effects of co-occurring stressors, appropriate spatial scales of analysis, extrapolation of response data among species and from organisms to populations, and imperfect knowledge and use of limited data sets. Further, different risk problems require varying degrees of sophistication, methodological refinement, and data quality. These issues suggest a number of research needs to improve methods for wildlife risk assessments, including continued development of population dynamics models to evaluate the effects of multiple stressors at varying spatial scales, methods for extrapolating across endpoints and species with reasonable confidence, stressor-response relations and methods for combining them in predictive and diagnostic assessments, and accessible data sets describing the ecology of terrestrial and aquatic species. Case study application of models and methods for assessing wildlife risk will help to demonstrate their strengths and limitations for solving particular risk problems.
\end{abstract}

Key Words: ecological risk assessment; multiple stressors; wildlife populations; extrapolation; population models; research needs

\section{INTRODUCTION}

Wildlife populations are experiencing increasing pressure from human-induced changes in the landscape. Human activity directly and indirectly influences the quality and quantity of habitat used by terrestrial and aquatic wildlife through introduction of stressors into the environment. Well-known examples of such stressors include alteration of habitat caused by patterns of agricultural and urban land use, introduced invasive and exotic species, nutrient enrichment, direct human disturbance, and toxic chemicals. More often than not, populations of wildlife are exposed to multiple stressors simultaneously, confounding the identification of causes of population decline and complicating their management.
Governmental regulatory agencies such as the U.S. Environmental Protection Agency (U.S. EPA) are required to assess the potential impacts of anthropogenic stressors to terrestrial and aquatic populations to support policy and management decisions affecting human use of the environment. Regulatory actions informed by such assessments include establishing stressor-specific environmental criteria and standards, e.g., ambient water quality criteria, that are protective of wildlife and aquatic life, regulating the types of pesticides and their uses to minimize risks to potentially exposed nontarget species, and managing toxic chemical exposure at hazardous waste sites. The objectives of resource management agencies and conservation groups differ somewhat from those of environmental regulatory agencies. The missions of trustee agencies, such as the National Marine Fisheries

${ }^{1}$ U.S. Environmental Protection Agency 
Service and the U.S. Fish and Wildlife Service, are oriented more toward establishing acceptable harvest rates of valued species, whereas those of conservation groups focus on protecting and restoring threatened and endangered species, habitats, and biodiversity. Despite these differences in mission, the actions of all organizations charged with wildlife issues must be accomplished in accordance with the goals of the Endangered Species Act, ensuring that regulated activities and exposures are protective of threatened and endangered species. To help generate and evaluate various options for environmental management, the U.S. EPA and other agencies have adopted decision support systems based on ecological risk assessment (e.g., U.S. EPA 1992, 1998, Power and McCarty 1998). Simply put, ecological risk assessment is a science-based process that can be used to evaluate the likelihood that adverse ecological effects can result from exposure to stressors in the environment.

As it has evolved from its original development in the 1980s, ecological risk assessment is intended to be a general, organizing process for science-based evaluations of the environmental consequences of human activity (see Suter et al. 2003 for a developmental history of ecological risk assessment). Thus, its concepts and approaches can be applied to problems involving any environmental stressor and the attributes of any species, community, or ecological system or process, i.e., the "assessment endpoint" in risk assessment parlance. As practiced, however, ecological risk assessment has been used for regulatory purposes primarily to support decisions pertaining to management of chemicals (Dorward-King et al. 2001). Further, and for a number of reasons, the majority of past ecological risk assessments, sensu stricto, have focused on survival, reproduction or individual growth of organisms as their primary measures of effect, that is, effects quantified at the organism-level of biological organization (Suter et al. 2003). For example, a fairly representative, albeit sophisticated, assessment, involving spent lead shot exposure to upland bird species (Kendall et al. 1996), characterized risk by comparing lead exposure from multiple pathways to lethal and sublethal organismlevel toxicity data. The stated assessment endpoint for this evaluation was "healthy and sustainable avian populations in upland habitats,"a populationlevel assessment endpoint. A similar illustration is offered by an assessment of the risk to monarch butterfly populations from exposure to $\mathrm{Bt}$ corn pollen (Sears et al. 2001), which related mortality and sublethal growth effects in monarch larvae to pollen exposure probabilistically. However, as has been argued many times (e.g., Barnthouse 1993, see also Barnthouse et al. 2006), risks to populations cannot be assessed comprehensively using organism-level toxicity data alone (but see Suter et al. 2005), owing to the spatial and temporal context of multiple stressors in the environment among other issues. Although they are informative of the effects experienced by wildlife and aquatic populations in human-dominated landscapes, such risk assessments may fail to provide the full array of information needed to support many of the objectives of regulatory, resource management and conservation organizations.

There has been a fair amount of attention given in recent years to improving wildlife risk assessment. Notably, a recent international workshop sponsored by the Society of Toxicology and Environmental Chemistry (SETAC) characterized the approaches and tools currently available for assessing risks to populations (Barnthouse et al. 2006). That workshop also explored a variety of legal, management, and scientific issues relevant to population-level risk, making recommendations that would improve the practice and use of population-level risk assessment in decision making. The SETAC workshop also developed a framework to help guide planning and implementation of a population-level ecological risk assessment following the standard ecological risk assessment framework provided by U.S. EPA (1992, 1998). Although this group concluded that such risk assessments could be conducted given the current state-of-the-science, it was clear that much work remains.

The purpose of this paper is to outline important science-based issues that affect the ability of environmental regulatory agencies to assess risks to wildlife. These issues suggest a variety of research and development needs that, with substantial additional progress, will advance the state of wildlife risk assessment. A research program being taken by the U.S. EPA and our partners is offered as an approach to address these needs. 


\section{CHALLENGE TO SCIENCE}

Given the history of ecological risk assessment, its typical practice, and the needs of environmental regulation and management, a significant challenge to the ecological research community is to develop scientifically valid approaches for assessing risks of multiple stressors to wildlife populations (Emlen et al. 2002). In a general sense, the concepts, theories, and methods of population ecology are sufficiently developed to conduct wildlife risk assessment, and examples of such assessments can be found in the literature in various forms (e.g., Doak et al. 1994, Akçakaya and Atwood 1997, Gervais and Anthony 2003). Despite this, key uncertainties and methodological limitations remain with respect to using wildlife risk assessment to support regulatory and other environmental management decisions affecting wildlife populations. Some of these relate to the adequacy of assessment approaches and tools, whereas others reflect the near-impossible challenge of having sufficient and necessary ecological data for all species of potential interest or concern.

A variety of methodological tools are available to wildlife risk assessment as the products of basic and applied research. Included are biological field survey and associated data analysis methods (Suter et al. 2000, White 2000), laboratory-based protocols for evaluating biological response to stressors, such as the various procedures codified by the American Society for Testing and Materials, and an array of mathematical models to evaluate the populationlevel consequences of stressor exposure (Emlen 1989, Barnthouse 1993, Burgman et al. 1993, Maltby et al. 2001, Beissinger and McCullough 2002, Pastorok et al. 2003, Burgman 2005, Munns et al. 2006). Despite the availability of such tools, the general absence of consensus frameworks that provide guidance for how they should be arranged and deployed can lead to ad hoc, and in the worst of cases inappropriate, applications of methods and models in wildlife risk assessments (Reed et al. 2002). Conceptual constructs are needed to guide how wildlife risk assessments should be conducted for a variety of environmental management problems and contexts. Guidance to help interpret the outputs of any particular tool, as well as that of the overall assessment, would improve the value of wildlife risk assessment to regulatory decision making (Biddinger et al. 2006).
There are also key gaps and limitations with respect to the tools themselves. One of the more vexing uncertainties pertains to the multiple stressors problem: populations exist in real landscapes that, more often than not, are being altered simultaneously by various combinations of human land use practices, changes in climate, and the introduction of nutrients, xenobiotic chemicals, nonnative and genetically-modified organisms, and other human-related stressors. Natural stressors, e. g., weather, competitors, and predators, also contribute to the mix of threats that populations must withstand to remain viable. A significant challenge is to define sound methods for describing and predicting the combined effects of multiple stressors on populations. The solution likely is not as straightforward as simple addition of effects; rather, some stressors may interact synergistically or antagonistically, such that their combined effect is greater or lesser than the sum of their individual effects. The timing of effect also is important, and has particularly acute implications for model-based assessments. For example, should a chemicalinduced effect precede or follow a weather-induced effect? This can create difficulties for assessments that attempt to predict future population outcomes as opposed to the less complex task of trying to understand the relationship between a particular stressor and population response. Substantial progress has been made on the narrower issue of chemical mixtures in the field of ecotoxicology, particularly when based on common modes of action (e.g., Bradbury et al. 1989, van den Berg et al. 1998, Lydy et al. 2004), but challenges remain in the face of combinations of stressors in addition to chemicals (see Foran and Ferenc 1999, Ferenc and Foran 2000). The multiple stressors problem may be less acute in assessments that assume the combined effects of multiple threats to be reflected in the empirical relationships linking various management options to attributes of specific populations. Wildlife risk assessments supporting stressor-specific regulation may need to account for combined stressor effects for that regulation to be effective.

Only somewhat less significant are methodological gaps in the ability to account for compensatory processes that influence population dynamics, and to accommodate issues of spatial context and scale. Including homeostasis of organism health, density dependence in the demographic rates of populations, and genetic change in populations that can occur randomly or directionally, compensatory 
processes result from dynamic mechanisms that are ignored or are reflected only rudimentarily in the population models typically used in ecological risk assessment (Moe 2006, Nacci and Hoffman 2006). This is not to say that approaches to account for compensatory processes do not exist conceptually or mathematically (e.g., Burgman 2005), but rather that sophistication in their use is limited by the current understanding of when and how compensatory processes are important (Reed et al. 2002). Assessments that fail to account for compensatory processes can yield risk predictions with considerable error (e.g., Nacci et al. 2002). Similarly, the spatial context of stressor exposure can also influence population outcomes. In addition to the obvious requirement of suitable habitat for a population to remain viable, the placement of habitats in relationship to the distributions of anthropogenic and natural stressors can significantly influence the exposure of populations to those stressors (Kapustka 2005). Although the toolbox of assessment methods that accommodate spatial context and heterogeneity is growing (Dunning et al. 1995, Hanski and Gaggiotti 2004), it is not always clear what tools and assessment scales are most informative in different environmental decision contexts. This issue is frequently encountered in decisions concerning hazardous waste site management and land use planning.

And then, there is the issue of data. As of early 2005, the list of threatened or endangered animal species numbered 518 in the U.S. alone (USFWS 2006). When combined with other terrestrial and aquatic species of regulatory, resource management and societal interest, the total number of species potentially involved as assessment populations for environmental decision making becomes overwhelming. Depending upon the informational requirements of the decision, a wildlife risk assessment involving any particular population might require data describing the species' life history and demographics, its use of habitats, and its susceptibilities and responses to any number of environmental stressors. The total combination of species, stressors, and environmental decision contexts potentially involved in a wildlife risk assessment represents an information challenge that cannot be addressed effectively in a piecemeal fashion. Meeting this challenge likely will require accumulating and organizing available data sets, and developing systems that enhance access to those data by wildlife risk assessors. Also, methods must be improved that will allow extrapolation of existing data to situations where data are lacking. Such is usually the case when chemical stressors are involved, as most of the information about biological effects is quantified as organism-level response. Thus, one aspect of this challenge is to refine the methods used to extrapolate response across levels of biological organization, i.e., from organisms to populations. Often, these methods take the form of population models developed for the assessment population or a surrogate. Adding to the problem is that the number of species for which stressor-response relationships are known is quite limited, requiring cross-species extrapolation to evaluate risk to untested species. For example, because the responses of threatened and endangered species rarely can be tested experimentally (e.g., Sappington et al. 2001), expectations of how they might respond to stressor exposure must be determined from the data base of other, tested species (e.g., Dwyer et al. 2005). Although empirical methods based on statistical relationships among taxa (Buckler et al.2005) or based on species sensitivity distributions (Posthuma et al. 2002) are useful in such situations, approaches based on mechanistic understanding of biological response may be of most value.

The research and developmental activities needed to address these challenges can be summarized as refinement of:

- methods and models to assess and diagnose the combined and relative risks of multiple stressors;

- models that reflect compensatory processes at population and evolutionary time scales;

- methods and models that account for spatial heterogeneity in stressor exposure, and that support delineation of the spatial scales at which wildlife risk assessments should be performed;

- data sets and systems needed for wildlife risk assessment, and mechanistic population models for particular species and classes of species that use those data;

- methods that allow extrapolation of effects across species and levels of biological organization; and 
- logical frameworks and guidance for conducting wildlife risk assessment to support a variety of environmental decision contexts.

The levels to which any of the above refinements are needed will vary with the environmental problem and rigor of answer needed. Further, these needs can be multifaceted, requiring advancement on several fronts to enhance our ability to assess risks to wildlife populations. Of course, there are other needs to be addressed, including further refinement of tools to accommodate stochastic events and various other forms of variability that can enhance assessment realism. Taken in the whole, however, additional progress in these six areas will substantially improve the usefulness of wildlife risk assessment as a decision support tool.

\section{AN APPROACH}

Recognizing the need for improved methods and information to support its decisions affecting wildlife, the U.S. EPA has developed a strategic plan to guide its wildlife risk assessment research. The goal of the Wildlife Research Strategy (U.S. EPA 2004) is to develop scientifically valid approaches for assessing risks to wildlife and other populations from multiple stressors in the environment. The U.S. EPA's approach reflects the contributions of three scientific disciplines (Fig. 1): ecotoxicology, population biology, and landscape ecology. The mechanistic research conducted at the nexus of these disciplines is focused in four key areas:

1. Mechanistically-based extrapolation research that improves the basis for predicting the responses of wildlife and other species from existing information;

2. Coordinated population biology and toxicology research that improves predictions of population dynamics in spatially heterogeneous landscapes;

3. Research that advances techniques for assessing the combined and relative risks of chemical and nonchemical stressors on wildlife and other populations; and

4. Research that supports definition of the spatial and temporal scales appropriate for wildlife risk assessments.

To assist in the identification of the specific research needed to attain its goal, the Wildlife Research Strategy communicates a conceptual approach for performing the analytical phases of populationlevel ecological risk assessments (Fig. 2). This approach begins with descriptions of real landscapes, referenced using GIS, as illustrated by the grid cell overlay in Fig. 2. Contained within these descriptions are the distributions of habitat and anthropogenic stressors that potentially affect the assessment endpoints of populations of wildlife and aquatic life. For all points referenced in the GIS description, data describing habitat quality and quantity, as well as the intensity of stressor exposure, are translated to effects on the basic demographic rates of survival and fecundity of organisms within the population using stressorresponse relationships and models. These demographic rates are used as input to mechanistic models, as represented using the notation of a population projection matrix model in Fig. 2, that describe the dynamics of subpopulations in each cell or pixel in the landscape. As a final step in this conceptualization, spatially organized subpopulations are allowed to communicate with one another through the movement of individual organisms, such that grid cells serve as sources or sinks within the population as a whole. Thus, the local effects of habitat and stressors are manifested across the landscape to determine overall population dynamics.

The research needed to effectuate this conceptual model, either in a general way or in support of specific wildlife risk assessments, focuses on (1) the development of data sources and tools to describe habitat and stressor distributions spatially; (2) the biological information needed to model the population; (3) stressor-response relationships to determine demographic response; (4) the mechanistically-based extrapolation methodologies needed to quantify such relationships when speciesspecific data are unavailable; (5) mechanistic population models to extrapolate effects on organisms to effects on populations; and (6) spatially explicit modeling approaches that account 
Fig. 1. The Wildlife Research Strategy at the intersection of the disciplines of ecotoxicology, population biology, and landscape ecology.

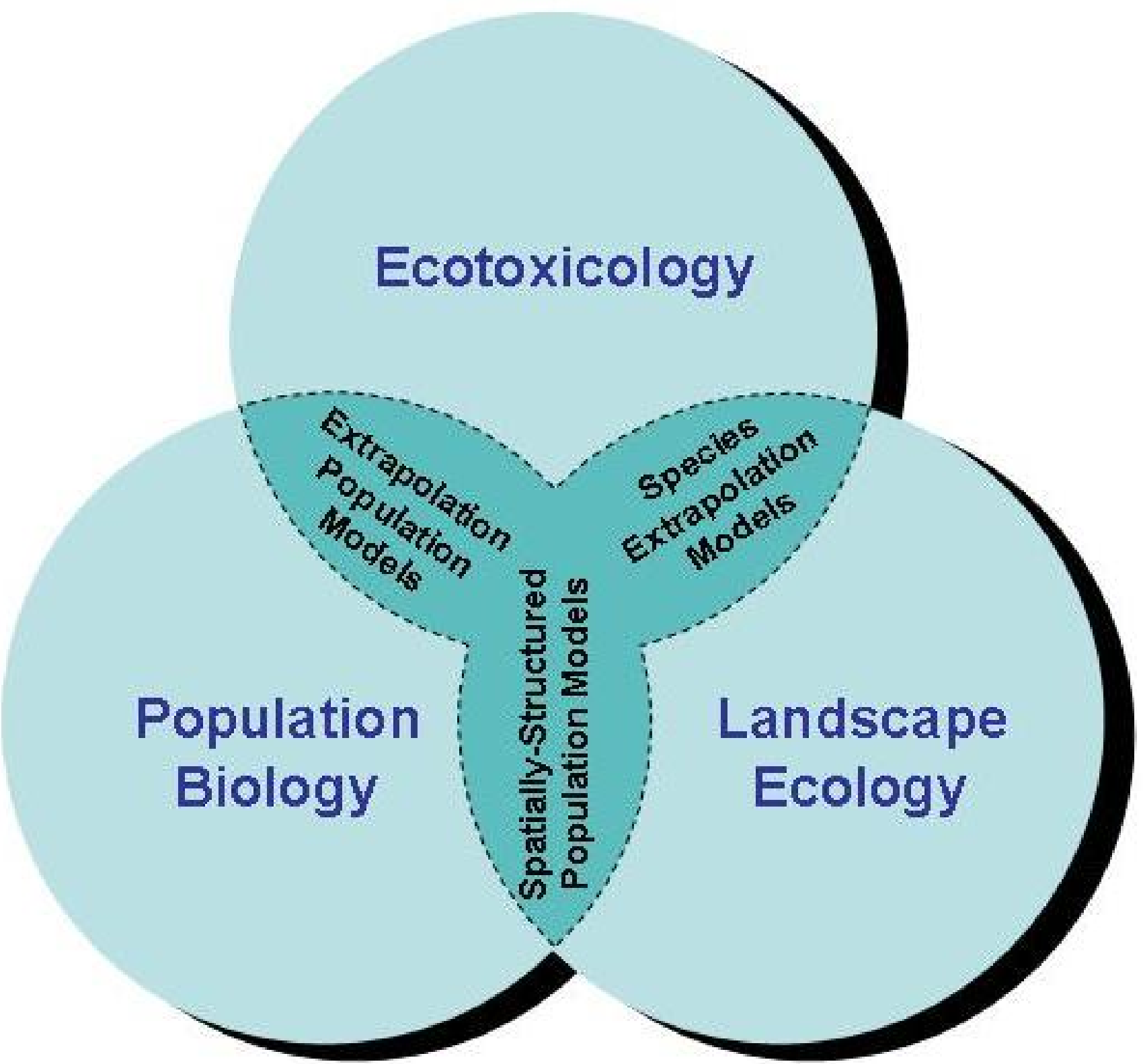

for spatial heterogeneity in the distributions of habitats, stressors and organisms. Collectively, the Wildlife Research Strategy addresses directly the first five research and development needs identified above.
The Strategy acknowledges that the degrees of accuracy and certainty required of wildlife risk assessments will vary across environmental management contexts. Some decisions may need only general appreciation of risks, whereas others may require highly detailed and site-specific 
Fig. 2. Conceptual approach for wildlife risk assessment.
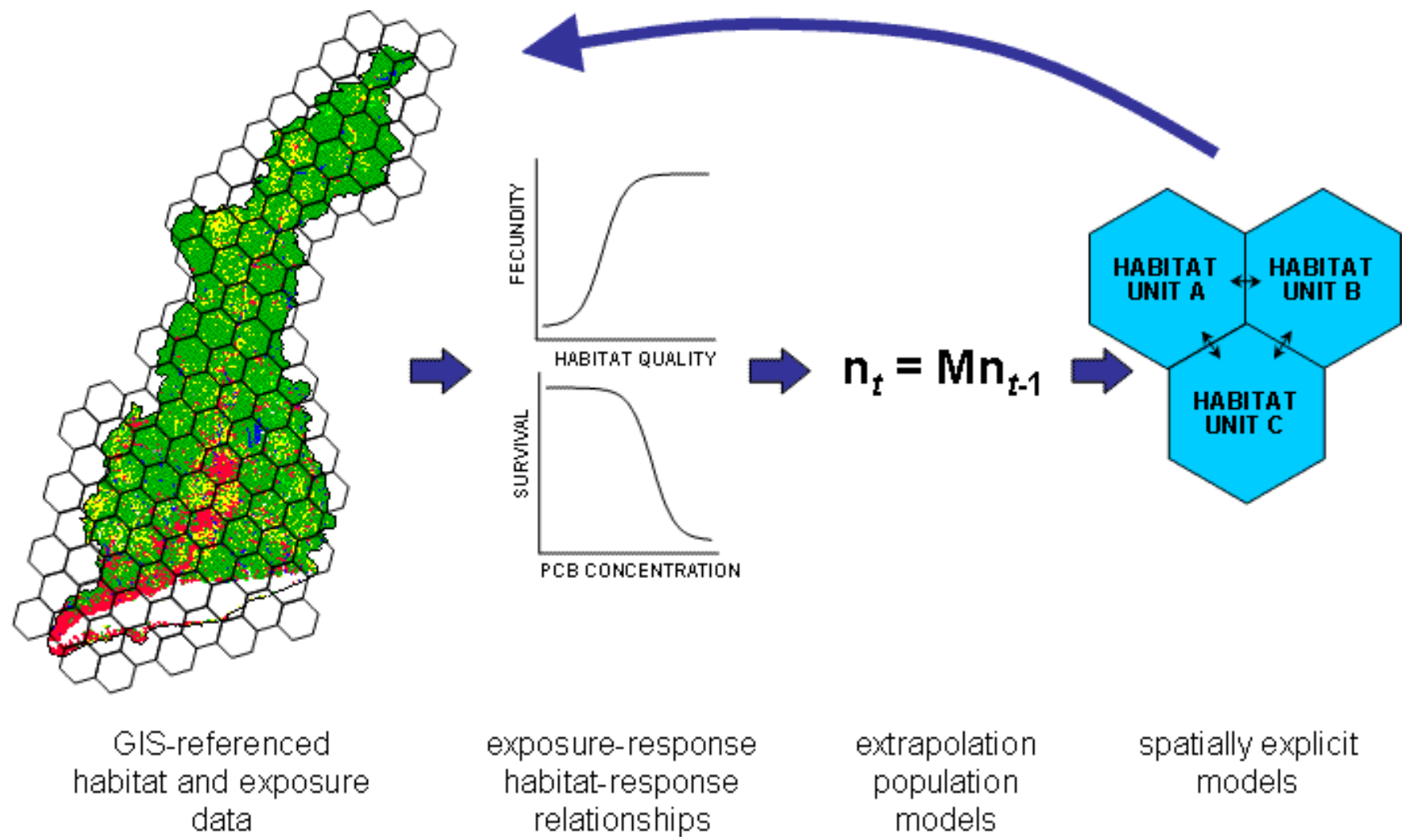
exposure-response
habitat-response
relationships
extrapolation
population
models
spatially explicit
models

descriptions of those risks. Reflecting this, the U.S. EPA's program is developing methods and models that vary in their levels of sophistication and data requirements. Simpler methods and models with limited data needs can be used in screening-level assessments to provide a "ball-park" understanding of risks. The estimates of risk produced at this level of assessment might be of a qualitative or binary nature, e.g., low/high, which can be used to determine whether risk management action is required, or if additional analysis is necessary to narrow uncertainties associated with risk estimates. Increasingly more ecologically realistic, accurate, and sophisticated methods and models will be used in progressively higher tiers of assessment when such approaches are needed to support decision making. The final, or definitive, tier of assessment is one that provides the information that is necessary and sufficient for the environmental manager to make a decision with an acceptable level of confidence. We envision a toolbox of approaches to be used in a tiered analysis and decision process, with complete risk assessments sequentially arrayed from screening to definitive levels (Fig. 3), in which the decision to move to higher tiers of assessment is determined by the level of confidence in the risk estimates needed by the decision maker, the resources available for the assessment, and the costs of making a wrong management decision (Fig. 3). Part of our effort is intended to explore the strengths and limitations of various assessment tools, and to capture that understanding in the form of broad guidance for conducting wildlife risk assessment to support a variety of environmental decisions.

In addition to developing the tools and data needed for wildlife risk assessment, the U.S. EPA is conducting efforts intended to illustrate the use of its research products in two demonstration projects. The first examines risks to terrestrial bird populations that result from agricultural pesticide application practices typical of the midwestern 
Fig. 3. Tiering of wildlife risk assessment, on the left showing iterations of the U.S. EPA $(1992,1998)$ process of ecological risk assessment, and on the right, the decision process for moving through the tiers.

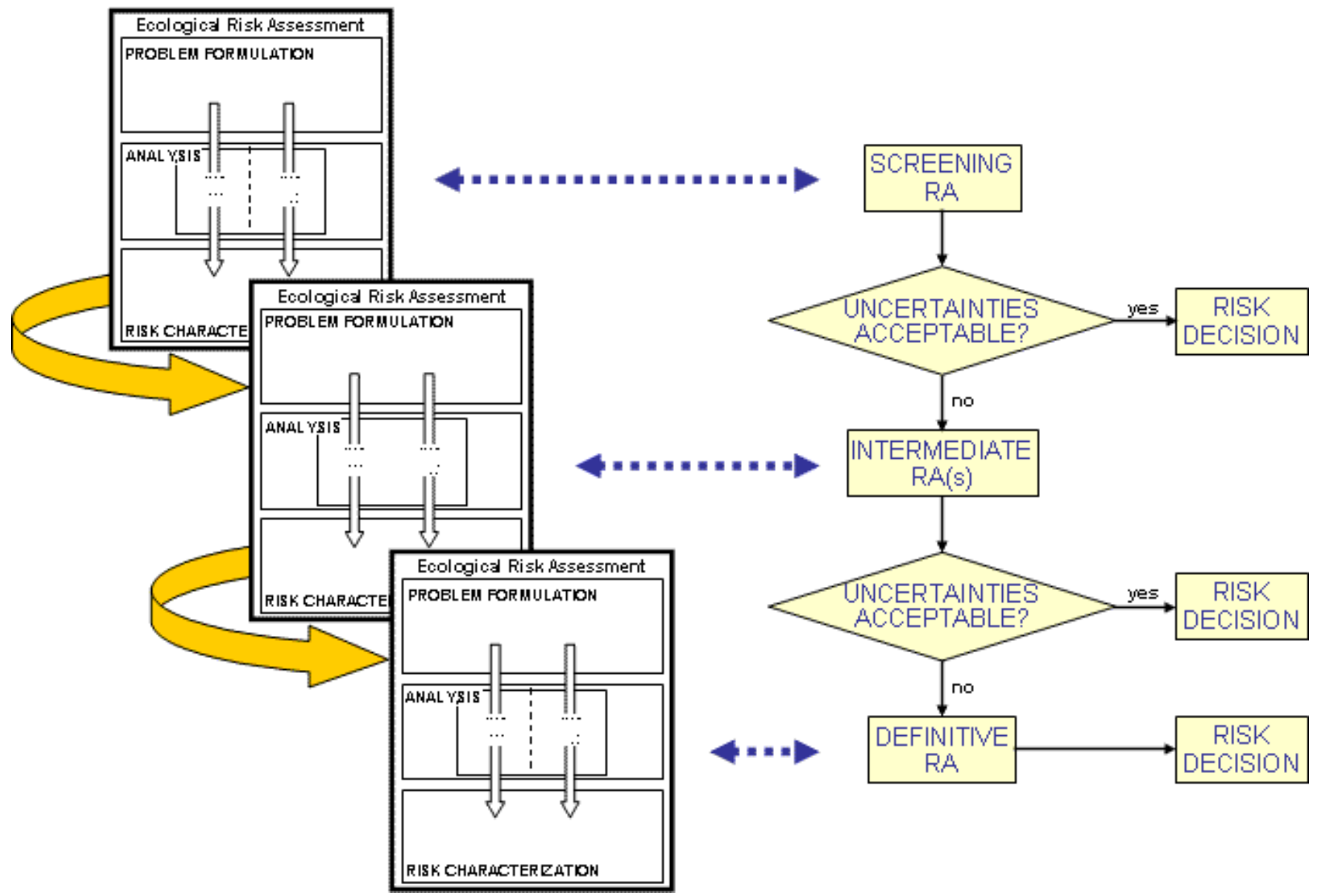

United States. This demonstration takes into account the patchwork nature of multiple plots interspersed with hedgerow and other land use, as well as differences in habitat use by bird species. The second assesses risks to the common loon, Gavia immer, resulting from mercury exposure, habitat change, and direct human disturbance (Nacci et al. 2005) to help guide development of environmental criteria protective of wildlife. Focusing initial development on New England and southeastern Canada, this effort will validate methods and patterns of risk predictions using information being obtained by research partners in the upper midwestern United States (Fevold et al. 2003, Kenow et al. 2003).
These demonstrations are serving multiple purposes. First and foremost, they provide specific opportunities to test and refine risk assessment methods. For example, the outputs of simple population models, lacking spatial definition and some aspects of biological realism, e.g., density dependence in demographic rates, are being compared with those of a spatially explicit model (Schumaker 1998) formatted for the agricultural pesticides project. Because such models differ in the kinds and amounts of data they require, these comparisons provide insights into the minimum data needed to assess risks adequately for different environmental management applications. Further, tools of similar sophistication, such as various population models that accommodate spatial 
context and heterogeneity, are being compared in the loon wildlife criteria demonstration to help define their relative strengths and limitations for a given application. Together with affiliated evaluations of the knowledge gained by increasing model complexity through incorporation of compensatory processes or stochasticity, these comparisons are intended to provide the insights needed for development of broad guidance for model selection and use.

The demonstrations also provide opportunities to evaluate key risk hypotheses relating to, for example, the relative importance of different stressors, and the combined effects of multiple stressors in affecting population stability and distribution. Because they mimic bona fide ecological risk assessments, the two efforts highlight additional research needed both generally with respect to wildlife risk assessment, and specifically for the particular risk problem evaluated. As importantly, the demonstrations are helping to support particular regulatory decisions faced by the U.S. EPA and others, e.g., pesticide registration in the agricultural pesticide demonstration, and environmental criteria protective of wildlife populations in the wildlife criteria demonstration. Once completed, these demonstration projects will also help to inform development of guidance for conducting wildlife risk assessments.

The U.S. EPA is collaborating with many other groups to implement the Wildlife Research Strategy. In addition to engaging the environmental community generally to advance the state of wildlife risk assessment science through the Science To Achieve Results (STAR) granting program (U.S. EPA 1996), more focused interactions have been developed with key groups to develop tools and data needed to meet the specific challenges described above. Some of these interactions, such as our partnerships with the New Hampshire Loon Preservation Committee and the Biodiversity Research Institute, center on aspects of the demonstration projects. Others address needs more broadly, such as collaboration with the Cornell Laboratory of Ornithology to improve accessibility to avian data sets accumulated through citizen science (see Hames, in press). The U.S. EPA also is helping to sponsor state-of-the-science symposia and workshops like the SETAC Workshop on Population-Level Ecological Risk Assessment (Barnthouse et al. 2006) to define issues and identify recommendations for research and implementation.
It is through these types of multidisciplinary and cross-organizational partnerships that advances in wildlife risk assessment will be made.

\section{CODA}

Environmental management attention is moving increasingly towards decisions that are based on risks to populations in the context of the multitude of anthropogenic stressors they face. Effective scientific support of such decision making requires a multidisciplinary approach, one that combines the perspectives and concepts of ecotoxicology, population biology, and landscape ecology (Hansen and Johnson 1999, Gervais and Regan 2006). The research required to advance this approach has both basic and applied components: basic research to move the theory of disciplines forward, and applied research to refine methods for particular decision problems and to help solve those problems. Substantial effort and resources will be needed to develop, refine, and demonstrate scientifically sound methods for wildlife risk assessment. Given its broad need by environmental regulatory agencies, resource management agencies, and conservation groups, and the scale of the challenge, this research will best be accomplished through collaboration and partnership.

Responses to this article can be read online at:

http://www.ecologyandsociety.org/voll1/iss 1/art23/responses/

\section{Acknowledgments:}

This paper was developed from a presentation given at the 2003 Wildlife Society Symposium on Assessing Risks to Wildlife Populations from Multiple Stressors, Burlington, Vermont, USA. The U.S. EPA Wildlife Research Strategy was conceived and developed by a core group including J. Baker, S, Bradbury, T. Gleason, T. Henry, S. Heppell, J. Nichols, N. Schumaker, and A. Trebitz. I thank D. Nacci and M. Nicholson for encouraging this paper, M. Burgman and H.R. Akçakaya for valuable discussions, and S. Ayvazian, D. Champlin, J. LiVolsi, T. Gleason, D. Nacci, M. Nicholson and two anonymous referees for timely and constructive 
reviews. Although the author of this paper is an employee of the U.S. EPA, the ideas described in herein do not necessarily reflect the policies of the Agency, and no official endorsement should be inferred. This is NHEERL contribution number AED-04-125.

\section{LITERATURE CITED}

Akçakaya, H. R., and J. L. Atwood. 1997. A habitat-based metapopulation model of the California gnatcatcher. Conservation Biology 11:422-434.

Barnthouse, L. W. 1993. Population-level effects. Pages 247-274 in G. W. Suter, II, editor. Ecological risk assessment. Lewis, Boca Raton, Florida, USA.

Barnthouse, L. W., W. R. Munns, Jr., and M. T. Sorensen, editors. 2006. Population-level ecological risk assessment. SETAC, Pensacola, Florida, USA, in press.

Beissinger, S. R., and D. R. McCullough. 2002. Population viability analysis. University of Chicago Press, Chicago, Illinois, USA.

Biddinger, G. R., P. Calow, P. Delorme, G. Harris, B. Hope, B.-L. Lin, M. T. Sorensen, P. van den Brink. 2006. Managing risk to ecological populations. in L. W. Barnthouse, W. R. Munns, Jr., and M. T. Sorensen, editors. Population-level ecological risk assessment. SETAC, Pensacola, Florida, USA, in press.

Bradbury, S. R. Carlson, and T. Henry. 1989. Polar narcosis in aquatic organisms. Aquatic Toxicology and Hazard Assessment 12:59-73.

Buckler, D. R., F. L. Mayer, M. R. Ellersieck, and A. Asfaw. 2005. Acute toxicity value extrapolation with fish and aquatic invertebrates. Archives of Environmental Contamination and Toxicology 49:546-58.

Burgman, M. A. 2005. Risks and decisions for conservation and environmental management. Cambridge University Press, New York, New York, USA.
Burgman, M. A., S. Ferson, and H. R. Akçakaya. 1993. Risk assessment in conservation biology. Chapman and Hall, London, UK.

Doak, D., P. Kareiva, and B. Klepetka. 1994. Modeling population viability for the desert tortoise in the western Mojave desert. Ecological Applications 4:446-460.

Dorward-King, E. J., G. W. Suter II, L. A. Kapustka, D. R. Mount, D. K. Reed-Judkins, S. M. Cormier, S. D. Dyer, M. G. Luxon, R. Parrish, and G. A. Burton, Jr. 2001. Distinguishing among factors that influence ecosystems. Pages 1-16 in D. J. Baird and G. A. Burton, Jr., editors. Ecological variability: Separating natural from anthropogenic causes of ecosystem impairment. SETAC, Pensacola, Florida, USA.

Dwyer, F. J., F. L. Mayer, L. C. Sappington, D. R. Buckler, C. M. Bridges, I. E. Greer, D. K. Hardesty, C. E. Henke, C. G. Ingersoll, J. L. Kunz, D. W. Whites, T. Augspurger, D. R. Mount, K. Hattala, G. N. Neuderfer. 2005. Assessing contaminant sensitivity of endangered and threatened aquatic species: Part I. Acute toxicity of five chemicals. Archives of Environmental Contamination and Toxicology 48:143-54.

Dunning, J., D. J. Stewart, B. J. Danielson, B. R. Noon, T. L. Root, R. H. Lamberson, E. E. Stevens. 1995. Spatially explicit population models: current forms and future uses. Ecological Applications 5:3-11.

Emlen, J. M. 1989. Terrestrial population models for ecological risk assessment: a state-of-the-art review. Environmental Toxicology and Chemistry 8:831-842.

Emlen, J., L. Kapustka, L. Barnthouse, N. Beyer, G. Biddinger, T. Kedwards, W. Landis, C. Menzie, W. Munns, M. Sorensen, and R. Wentsel. 2002. Ecological resource management: a call to action. Bulletin of the Ecological Society of America 83:269-271.

Foran, J. A., and S. A. Ferenc. 1999. Multiple stressors in ecological risk and impact assessment. SETAC, Pensacola, Florida, USA.

Fevold, B. M., M. W. Meyer, P. W. Rasmussen, and S. A. Temple. 2003. Bioaccumulation patterns and temporal trends of mercury exposure in 
Wisconsin common loons. Ecotoxicology 12:83-93.

Ferenc, S. A., and Foran, J. A. 2000. Multiple stressors in ecological risk and impact assessment: approach to risk estimation. SETAC, Pensacola, Florida, USA.

Gervais, J. A., and R. G. Anthony. 2003. Chronic organochlorine contaminants, environmental variability, and the demographics of a burrowing owl population. Ecological Applications 13:1250-1262.

Gervais, J. A., and H. M. Regan. 2006. What conservation biology and natural resource management can offer population-level ecological risk assessment. in L. W. Barnthouse, W. R. Munns, Jr., and M. T. Sorensen, editors. Population-level ecological risk assessment. SETAC, Pensacola, Florida, USA, in press.

Hames, R. S. 2006. Broad-scale assessment of risk to neotropical migrant bird species of multiple human causes: acid rain and habitat fragmentation. Ecology and Society, in press.

Hansen, L. J., and M. L. Johnson. 1999. Conservation and toxicology: integrating the disciplines. Conservation Biology 13:1225-1227.

Hanski, I., and O. E. Gaggiotti, editors. 2004. Ecology, genetics, and evolution of metapopulations. Elsevier Academic, San Diego, California, USA.

Kapustka, L. A. 2005. Assessing ecological risks at the landscape scale: opportunities and technical limitations. Ecology and Society 10(2):11.

Kendall, R. J., T. E. Lacher, Jr., C. Bunck, B. Daniel, C. Driver, C. E. Grue, F. Leighton, W. Stansley, P. G. Watanabe, and M. Whitworth. 1996. An ecological risk assessment of lead shot exposure in non-waterfowl avian species: upland game birds and raptors. Environmental Toxicology and Chemistry 15:4-20.

Kenow, K. P., S. Gutreuter, R. K. Hines, M. W. Meyer, F. Fournier, and W. H. Karasov. 2003. Effects of methyl mercury exposure on the growth of juvenile common loons. Ecotoxicology 12:171-181.

Lydy, M., J. Belden, C. Wheelock, B. Hammock, and D. Denton. 2004. Challenges in regulating pesticide mixtures. Ecology and Society 9(6):1. [online] URL: http://www.ecologyandsociety.org/ vol9/iss6/art1/.

Maltby, L., T. J. Kedwards, V. E. Forbes, K. Grasman, J. E. Kammenga, W. R. Munns, A. H. Ringwood, J. S. Weis, and S. N. Wood. 2001. Linking individual-level responses and populationlevel consequences. Pages 27-82 in D. J. Baird and G. A. Burton, editors. Ecological variability: separating natural from anthropogenic causes of ecosystem impairment. SETAC, Pensacola, Florida, USA.

Moe, S. J. 2006. Density dependence in ecological risk assessment. In L. W. Barnthouse, W. R. Munns, Jr., and M. T. Sorensen, editors. Population-level ecological risk assessment. SETAC, Pensacola, Florida, USA, in press.

Munns, W. R., Jr., J. Gervais, A. A. Hoffman, U. Hommen, D. E. Nacci, M. Nakamaru, R. Sibly, and C. J. Topping. 2006. Modeling approaches to population-level ecological risk assessment. in $\mathrm{L}$. W. Barnthouse, W. R. Munns, Jr., and M. T. Sorensen, editors. Population-level ecological risk assessment. SETAC, Pensacola, Florida, USA, in press.

Nacci, D. E., and A. A. Hoffman. 2006. Genetic variation in population-level ecological risk assessment. in L. W. Barnthouse, W. R. Munns, Jr., and M. T. Sorensen, editors. Population-level ecological risk assessment. SETAC, Pensacola, Florida, USA, in press.

Nacci, D. E., T. R. Gleason, R. Gutjahr-Gobell, M. Huber, and W. R. Munns, Jr. 2002. Effects of chronic stress on wildlife populations: a modeling approach and case study. Pages 247-272 in M. C. Newman, M. H. Roberts, Jr., and R. C. Hale, editors. Coastal and estuarine risk assessment: risk on the edge. CRC/Lewis, New York, New York, USA.

Nacci, D. E., M. Pelletier, J. Lake, R. Bennett, R. Haebler, J. Grear, A. Kuhn, M. Nicholson, and W. R. Munns, Jr. 2005. An approach to predict risks to wildlife populations from mercury and other stressors. Ecotoxicology 14:283-293.

Pastorok, R. A, H. R. Akçakaya, H. Regan, S. Ferson, S. M. Bartell. 2003. Role of ecological modeling in risk assessment. Human and Ecological Risk Assessment 9:939-972. 
Posthuma, L., G. W. Suter II, and T. P. Traas, editors. 2002. Species sensitivity distributions in ecotoxicology. Lewis, Boca Raton, Florida, USA.

Power, M., and L. S. McCarty. 1998. A comparative analysis of environmental risk assessment and management frameworks. Environmental Science and Technology 32:224A-231A.

Reed, J. M., L. S. Mills, J. B. Dunning Jr., E. S. Menges, K. S. McKelvey, R. Frye, S. R. Beissinger, M.-C. Anstett, and P. Miller. 2002. Emerging issues in population viability analysis. Conservation Biology 16:7-19.

Sappington, L. C., F. L. Mayer, F. J. Dwyer, D. R. Buckler, J. R. Jones, and M. R. Ellersieck. 2001. Contaminant sensitivity of threatened and endangered fishes compared to standard surrogate species. Environmental Toxicology and Chemistry 20:2869-2876.

Sears, M. K., R. L. Hellmich, D. E. Stanley-Horn, K. S. Oberhauser, J. M. Pleasants, H. R. Mattila, B. D. Siegfried, and G. P. Dively. 2001. Impact of Bt corn pollen on monarch butterfly populations: a risk assessment. Proceedings of the National Academy of Sciences 98:11937-11942.

Schumaker, N. H. 1998. A users guide to the PATCH model. EPA/600/R-98/135, Office of Research and Development, Corvallis, Oregon, USA.

Suter, G. W., II, R. A. Efroymson, B. E. Sample, and D. S. Jones, editors. 2000. Ecological risk assessment for contaminated sites. Lewis, Boca Raton, Florida, USA.

Suter, G. W., II, S. B. Norton, and L. W. Barnthouse. 2003. The evolution of frameworks for ecological risk assessment from the Red Book ancestor. Human and Ecological Risk Assessment 9:1349-1360.

Suter, G. W., II, S. B. Norton, and A. Fairbrother. 2005. Individuals versus organisms versus populations in the definition of ecological assessment endpoints. Integrated Environmental Assessment and Management 1:1-4.

U.S. EPA. 1992. Framework for ecological risk assessment. EPA/630/R-92/001, Risk Assessment Forum, Washington, D.C., USA.
U.S. EPA. 1996. Science to Achieve Results (STAR) educational support programs. Washington, D.C., USA. Available online at: http://es.epa.gov/ncer/.

U.S. EPA. 1998. Guidelines for ecological risk assessment. EPA/630/R-95/002F, Risk Assessment Forum, Washington, D.C., USA.

U.S. EPA. 2004. Wildlife research strategy. EPA 600/R-04/050, Office of Research and Development, Research Triangle Park, North Carolina, USA. Available online at: www.epa.gov/nheerl/publications/ files/wildlife research strategy $2205 . p d f$.

U.S. Fish and Wildlife Service (USFWS). 2006. USFWS Threatened and Endangered Species System (TESS). Available online at: http://ecos.fws. gov/tess public/TESSBoxscore.

van den Berg, M., L. Birnbaum, A. T. C. Bosveld, B. Brunström, P. Cook, M. Feeley, J. P. Giesy, A. Hanberg, R. Hasegawa, S. W. Kennedy, T. Kubiak, J. C. Larsen, F. X. R. van Leeuwen, A. K. D. Liem, C. Nolt, R. E. Peterson, L. Poellinger, S. Safe, D. Schrenk, D. Tillitt, M. Tysklind, M. Younes, F. Waern, and T. Zacharewski. 1998. Toxic equivalency factors (TEFs) for PCBs, PCDDs, PCDFs for humans and wildlife. Environmental Health Perspectives 106:775-792.

White, G. C. 2000. Population viability analysis: data requirements and essential analyses. Pages 288-331 in L. Boitani and T. K. Fuller, editors. Research techniques in animal ecology: controversies and consequences. Columbia University Press, New York, New York, USA. 